aly.

uaudo es vi sauto? Sl fa edxd de Oristo. i Sucubilic $q^{\prime} / \mathrm{paz}$ ar....

¿cuauds es?

ecuets Java estos des detalles Ha 28. il corté de IL. IS Siones de Cete agne jadi

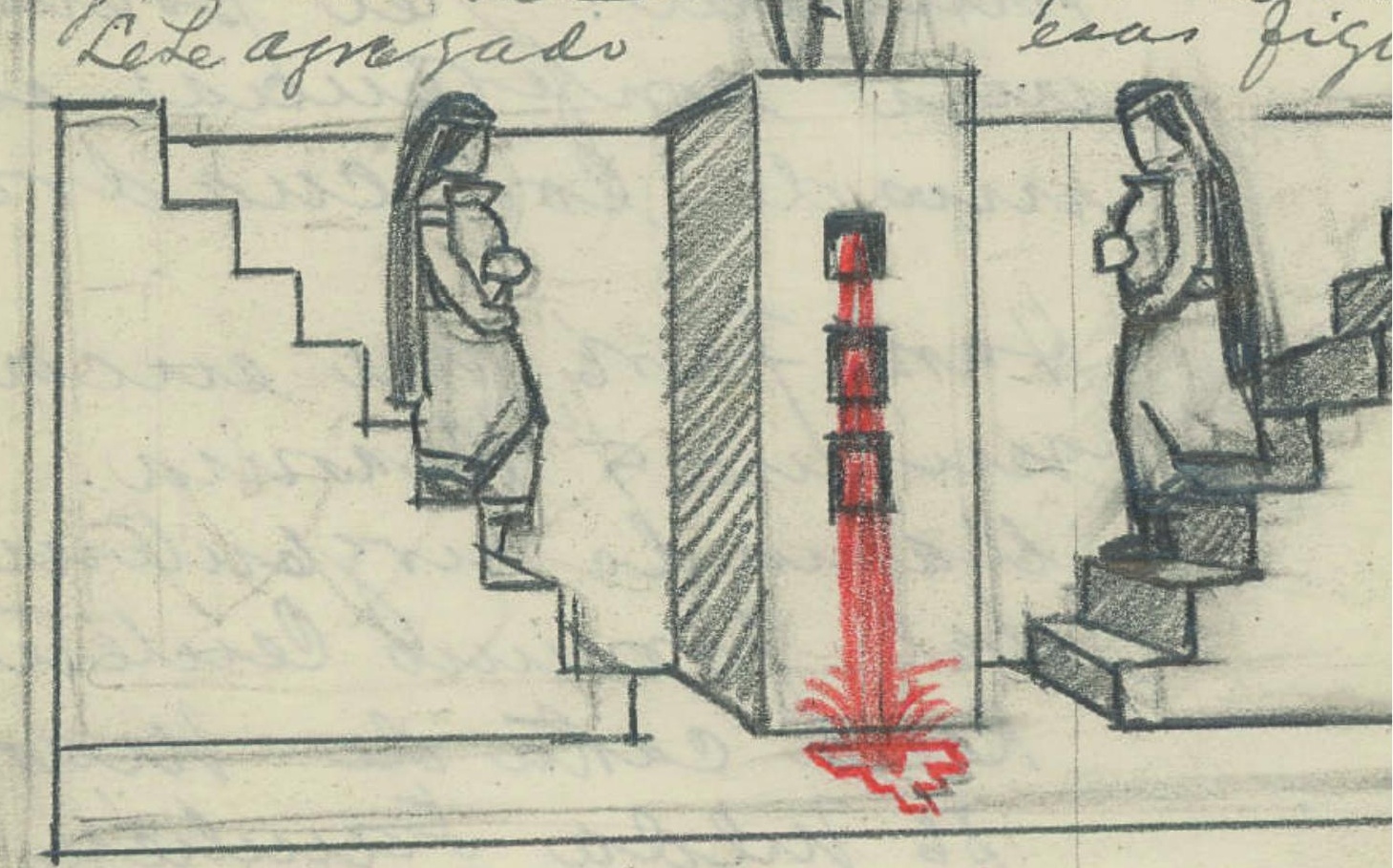

mas para sugevide. Co de ray 


\title{
El manifiesto artístico de Alejandro González Trujillo, Apu-Rimak, en sus cartas a Yolanda Bedregal
}

\author{
Alejandra Echazú Conitzer \\ Universidad Católica Boliviana San Pablo \\ aechazu@ucb.edu.bo \\ La Paz - Bolivia \\ Rodrigo Gutiérrez Viñuales \\ Universidad de Granada \\ rgutierr@ugr.es \\ Granada-España
}

\begin{abstract}
Resumen
A partir de un amplio conjunto de cartas, hasta ahora inéditas, escritas por el artista peruano Alejandro González Trujillo, y enviadas a la joven escritora boliviana Yolanda Bedregal entre 1934 y 1936, hemos extractado diversas reflexiones que nos dan la posibilidad de componer una suerte de manifiesto artístico del pintor. Las cartas permiten recrear ese periodo cusqueño de González Trujillo, su vida, sus afanes y sus trabajos en viajes artísticos y patrimoniales por el sur del Perú, a la par que evocar su disciplina y formación en la vida y en el arte, así como su profunda vocación de educador. Sus pensamientos dejan entrever un compromiso inquebrantable con la cultura peruana prehispánica, con su propio arte y su posición dentro de las tensiones del campo artístico peruano de esos años. Se pone también en evidencia el fervor con el que los artistas peruanos abordaron la inconmensurable labor de catalogar el legado de sus ancestros.

Palabras clave: Alejandro González Trujillo, Apu-Rimak, Yolanda Bedregal, Cusco, La Paz, arte contemporáneo, enseñanza artística, indoamericanismo, siglo XX
\end{abstract}

\begin{abstract}
From a wide range of letters, hitherto unpublished, by the Peruvian artist Alejandro González Trujillo, and sent to the young Bolivian writer Yolanda Bedregal 1934 and 1936, we have extracted various reflections that give us the possibility of composing a kind of artistic manifesto by the painter. The letters allow us to recreate that Cusco period of González Trujillo, his life, his efforts, and his works in artistic and patrimonial journeys through the south of Peru while evoking his discipline training in life and art, as well as his profound vocation as an educator. His thoughts reveal an unwavering commitment to pre-Hispanic Peruvian culture, his art, and his position within the tensions of the Peruvian artistic field of those years. It also shows the fervor with which Peruvian artists approached the immeasurable task of cataloging their ancestors' legacy.
\end{abstract}

Keywords: Alejandro González Trujillo, Apu-Rimak, Yolanda Bedregal, Cusco, La Paz, contemporary art, art education, Indo-Americanism, 20th century

\section{Introducción}

Ante un conjunto de cartas escritas por el artista peruano Alejandro González Trujillo a la joven escritora boliviana Yolanda Bedregal, en un arco de tiempo que abarca desde 1934 hasta 1936, consideramos oportuno, para componer el presente ensayo, extractar de ellas 
varias reflexiones que nos permiten componer una suerte de manifiesto artístico inédito del pintor. Este trabajo intenta sumar nuevos peldaños a las investigaciones realizadas por María Sol Romero Sommer, cristalizadas tanto en el catálogo que acompañó la exposición retrospectiva de González Trujillo, que ella misma coordinó en la Asociación Cultural Peruano Británica (2011), como en su tesis de maestría (2015). ${ }^{1}$

Alejandro González Trujillo y Yolanda Bedregal se conocieron el 26 de marzo de 1934 en Cusco, ${ }^{2}$ lugar a donde la boliviana había llegado como parte de una embajada cultural con motivo de los festejos por el IV centenario de la fundación española de la ciudad. El encuentro dejó en ambos una huella muy profunda, al compartir similares ideales y búsquedas en el arte. González Trujillo era trece años mayor que la joven Bedregal, quien en ese entonces tenía 22; durante dos años, él le escribió sobre sus viajes por el sur del Perú, sus convicciones y descubrimientos del arte indoamericano (como él lo llamaba), y le señaló las que consideraba mejores sendas para comprender el arte indígena. La fina sensibilidad de Bedregal intuyó que esas cartas contenían el espíritu de quien tanto la había apoyado a crear y a crecer artísticamente, y por ello las conservó.

Es evidente que entre ambos se despertaron afinidades espirituales ${ }^{3}$ y las cartas dan testimonio de que Apu-Rimak se convirtió en una suerte de mentor artístico de la joven, inclusive diseñando para ella un taller de modelado. ${ }^{4}$ El valor de esta correspondencia se ramifica en algunos tópicos, que son los que resaltaremos en este trabajo: a) Recrea el periodo cusqueño de González Trujillo: su vida, sus afanes y sus trabajos en misiones por el sur del Perú; su disciplina y formación en la vida y en el arte, así como su profunda vocación de educador. b) Revela el manifiesto artístico de Apu-Rimak y su compromiso inquebrantable con la cultura peruana prehispánica y con su propio arte. Queda también en evidencia el fervor con el que abordaron los artistas peruanos la inconmensurable labor de catalogar el legado de sus ancestros.

Yolanda Bedregal había nacido en La Paz en 1913, en el seno de una familia modesta pero muy reconocida intelectualmente. Su padre, Juan Francisco Bedregal, destacó en derecho, literatura, periodismo y educación; hombre culto y académico, fue el primer rector autónomo de la Universidad Mayor de San Andrés, fundador de la Academia Boliviana Correspondiente de la Real Academia de la Lengua, de la que fue presidente y director perpetuo. Fue también presidente del Círculo de Bellas Artes, organizó el PEN Club de Bolivia y formó parte de numerosas asociaciones académicas. Por su casa pasaban habitualmente intelectuales y célebres escritores, como Alcides Arguedas, José Eduardo Guerra, Armando Chirveches o el compositor y cineasta José María Velasco Maidana. En este ambiente era lógico que el padre respaldara de manera decisiva la vocación literaria y artística de su hija. Yolanda compartía la afición por el arte plástico y la danza con sus amigas Marina y Nilda Nuñez del Prado (quienes destacarían en la escultura y la orfebrería, respectivamente).

1 Con gran generosidad, María Sol Romero Sommer puso a nuestra disposición todo lo compilado en los años de su investigación. Le quedamos muy agradecidos. También a Cristina Machicado, de la Fundación Flavio Machicado Vizcarra (La Paz), por la ayuda con escaneos y fotografiados de las obras reproducidas en este trabajo.

2 Archivo Yolanda Bedregal, La Paz —en adelante, AYB—. Carta de Alejandro González Trujillo a Yolanda Bedregal, Cusco, 26 de marzo de 1935.

3 Inclusive González Trujillo, en cuanto a complicidad, compara en varias cartas a Yolanda Bedregal con quien había sido su íntimo amigo, el pintor Jorge Vinatea Reinoso, fallecido en 1931: "[...] en ti siento resucitar a Jorge, ese Jorge en quien volqué mis penas, mis quejas, mis inquietudes, que fue rebelde ante las injusticias, bueno como el pan y que murió como una paloma” (AYB. Carta del 29 de abril de 1934); "[...] eres mi Jorge, porque he encontrado a Jorge en ti" (AYB. Carta del 17 de junio de 1934).

4 Al respecto, y dado el potencial de los materiales documentales hallados, estamos elaborando un artículo específico que incluirá el proyecto trazado por Apu-Rimak, con detalles del armado y construcción del mismo, sugerencias para la elaboración de accesorios y un conjunto de diseños originales realizados por el artista peruano. 
La trayectoria artística de Apu-Rimak había comenzado a definirse en las aulas de la Escuela Nacional de Bellas Artes (ENBA), fundada en Lima en 1919 bajo la dirección del maestro Daniel Hernández, junto, entre otros, a su gran amigo Jorge Vinatea Reinoso, a Elena Izcue o a Julia Codesido. Aun sin dedicarse a la escultura, Apu-Rimak o la propia Izcue se habían arrimado al encargado de la enseñanza de esta disciplina, el español Manuel Piqueras Cotolí y, más aún, cuando este fue derivando hacia sus prácticas arquitectónicas dentro de la vertiente "neoperuana". A partir de 1926, Apu-Rimak estará vinculado a Julio C. Tello y al Museo de Arqueología Peruana; durante catorce años se dedicará a estas investigaciones, tanto en aquella institución como en el Museo Nacional de Lima y el Instituto Arqueológico del Cusco, trabajando junto a Luis E. Valcárcel (Romero Sommer, 2015), dando inicio a una febril acción consistente en documentarse en museos arqueológicos y colecciones de arte peruano antiguo, incorporando en sus trabajos representaciones, signos, ornamentos y cromatismos tomados de la arquitectura, la cerámica y los textiles (Fig. 1).

\section{Yolanda Bedregal y la "embajada artística" boliviana en el Cusco (1934). El encuentro con Apu-Rimak}

A inicios de los años 30, mientras Apu-Rimak (Fig. 2) establecido temporalmente en Cusco- - se afianzaba en sus convicciones ancestralistas, en Bolivia varios intelectuales, literatos, arqueólogos, arquitectos y artistas transitaban caminos ideológicos similares, desarrollando diversas prácticas en el ámbito de lo precolombino/ precolombinista y lo indianista desde una perspectiva contemporánea. La cultura tiwanacota adquirió una significación particular, al convertirse en una fuente de filiación e identidad nacional. ${ }^{5}$

A finales de 1931, y en el marco de la llamada Semana Indianista-Cruzada Pro-Arte Nativo (La Paz, 19 al 27 de diciembre), se llevó a cabo un Salón Indianista de arte, en el que el pintor David Crespo Gastelú -a quien nos referiremos en breve- recibió el Primer Premio "Kantuta de Oro". Entre los expositores figuraron algunos

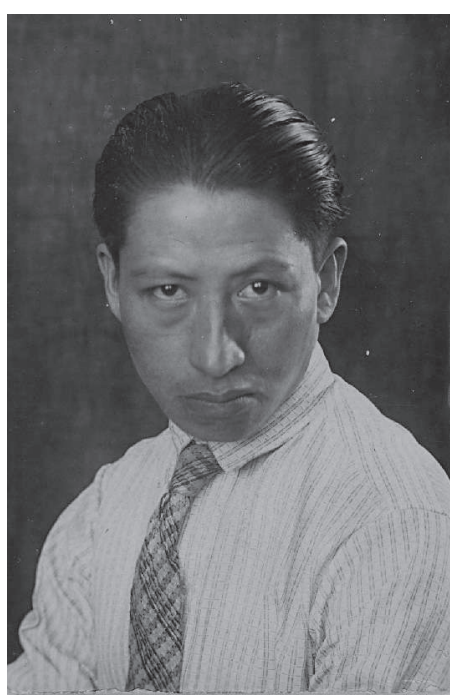

Fig. 2: Autor desconocido. Alejandro González Trujillo Apu-Rimak (1934). Gelatina de plata sobre papel. Archivo Yolanda Bedregal, La Paz.

5 Ver, por ejemplo, los artículos de Enrique Riobó Pezoa (2019) y Omar Rocha Velasco (2019). 


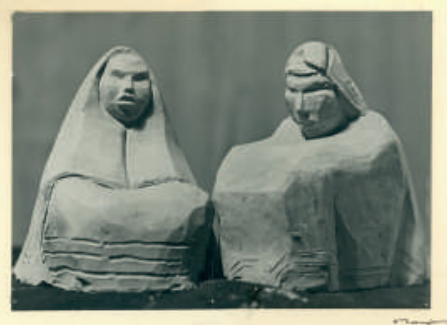

Fig. 3: Yolanda Bedregal. Tipos andinos. Esculturas modeladas en barro (c.1935). Gelatina de plata sobre papel. (Fotografía de Mayer, 1949). Archivo Yolanda Bedregal, La Paz.

no Gonzalo, el matrimonio conformado por la escritor Gastelú, y las hermanas Marina y Nilda Núñez del Prado. Llevaban consigo un conjunto de obras, con el fin de ser expuestas allí: "43 expléndidas (sic) pinturas firmadas por David Crespo Gastelú, Cecilio Guzmán de Rojas, Jorge De la Reza y Germán Villazón, 2 dibujos en cobre, de José M. Velasco Maidana, 6 esculturas de Marina Núñez del Prado y Yolanda Bedregal (Fig. 3), de exquisita factura ccolla". La muestra se realizó en el Teatro Municipal del Cusco, entre el 5 y el 11 de abril de aquel año (Kuon y otros, 2009, p. 73).

Como recuerda Marina, de la inauguración "tomaron parte personalidades de la localidad, como el Dr. Rafael Aguilar, Rector de la Universidad, el sociólogo y escritor, Dr. Uriel García, autor del Nuevo Indio, Yolanda Bedregal, que declamó sus versos y mi hermana Nilda

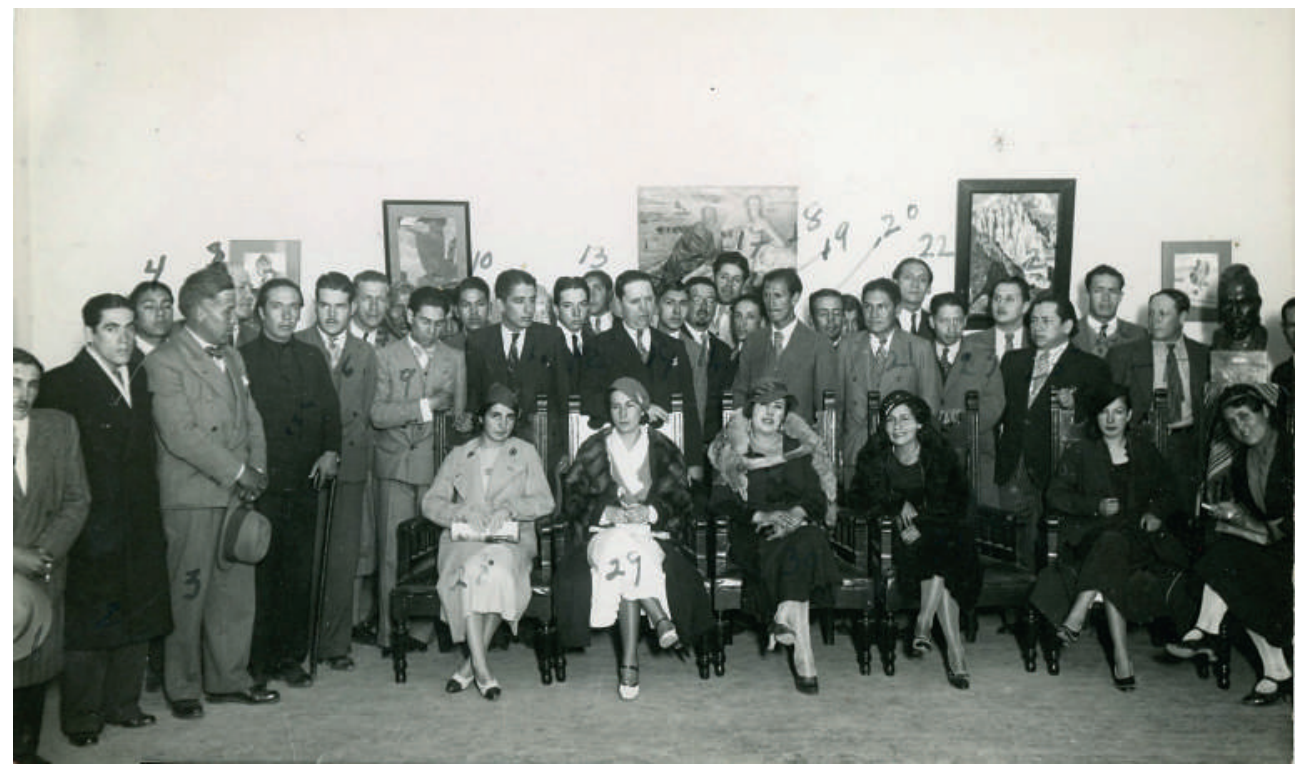

Fig. 4: Inauguración de la exposición de arte boliviano. Teatro Municipal de Cusco, 5 de abril de 1934. Gelatina de plata sobre papel. Entre otros puede verse a Paco Guzmán (5), Roberto Latorre (11), Gonzalo Bedregal (12), Mariano Fuentes Lira (13), Rafae Aguilar (14), Francisco Olazo (18), David Crespo Gastelú (19), Alejandro González Trujillo (23), Fortunato Salvatierra (25), Yolanda Bedregal (28), Marina Núñez del Prado (29), Nilda Núñez del Prado (32). En la pared del fondo, al centro, se ve el óleo América y Europa (1933) de Cecilio Guzmán de Rojas. Archivo Yolanda Bedregal, La Paz. 
que leyó poemas de poetas bolivianos. El escritor Gover Zárate ${ }^{6}$ hizo la presentación de los artistas expositores" (Núñez del Prado, 1973, p. 32) (Fig. 4). Además de los eventos artísticos, los artistas e intelectuales cusqueños prepararon cuidadosamente ágapes y actos sociales para los invitados bolivianos, como la cena que el 8 de abril ofrecieron "los pintapacuc", con un menú impreso en quechua.

Los visitantes dedicaron los días de la estancia en la ciudad a recorrer los monumentos precolombinos y coloniales de la misma, así como los alrededores (entre otros sitios visitaron Anta, Chinchero, Ollantaytambo, Pisac, Sacsayhuamán, San Jerónimo y San Sebastián), y coincidieron felizmente, unos días antes de la exposición, con los días de Semana Santa, pudiendo disfrutar de sus oficios y procesiones, en especial la del Taytacha Temblores del Viernes Santo. ${ }^{7}$ No obstante, recordaba Núñez del Prado (1973, p. 33), quedaba pendiente "la etapa más emocionante: la peregrinación a Machu Picchu”. Junto a los bolivianos formaron parte de la expedición, entre otros, los escritores cusqueños Roberto Latorre y José Uriel García, el escultor Paco Guzmán, los pintores Alejandro González Trujillo y Francisco Olazo, ${ }^{8}$ y el fotógrafo Martín Chambi, quien realizaría una serie de fotos de Yolanda Bedregal y las hermanas Núñez del Prado vestidas de cusqueñas durante una fiesta de domingo en su casa (Fig. 5).

Roberto Latorre firmaría en noviembre de 1935 el prólogo al libro que, tres años después, publicarían en La Paz, Gloria Serrano y David Crespo Gastelú, ${ }^{9}$ bajo el título Tierras del Kosko (Fig. 6). Crespo Gastelú fue autor del amplio conjunto de ilustraciones que se integran en la obra: pinturas (emparentadas con estéticas sabogalinas y cercanas a Enrique Camino Brent), dibujos y viñetas xilográficas realizadas a partir de aquel viaje. El libro se dividía en "catorce frisos" o capítulos, firmados entre el 23 de marzo y el 31 de mayo de 1934 (aunque en el libro no están ordenados cronológicamente), lo cual nos da un rango de fechas aproximado de la estancia de los artistas bolivianos en Cusco y su región. De esos "frisos", en vinculación a nuestro centro de atención, sobresale el último de ellos, dedicado, como punto culminante del libro, al viaje en tren y a la "penosa ascensión” a Machu Picchu, el

6 El periodista potosino Góver Zárate Mena residía en Cusco, por instrucciones del Gobierno boliviano, con el fin de fundar y publicar allí el periódico Última Hora, el cual tenía como intención ganar adeptos para la causa boliviana en la guerra (Echazú, 2019). Fue precisamente Zárate quien recibió a la comitiva boliviana y participó de todas las actividades.

7 Yolanda Bedregal, entre los “Apuntes cuzqueños” de su Poemar (1937), incluirá un poema a la Semana Santa aludiendo al Taytacha Temblores (imagen que tenía presencia en el cuarto-estudio de Apu-Rimak). Asimismo, en el último poema de la serie menciona a Martín Chambi.

8 Olazo concretaría en esos años una serie de acuarelas, organizada en dos volúmenes, titulada 100 motivos de la decoración inka. Las mismas ingresaron a la colección del Museo de Arte de Lima en 2015 y fueron expuestas en la itinerancia llevada a cabo en ese museo de la exposición Redes de vanguardia. Amauta y América Latina, 1926-1930 en 2019.

9 La primera colaboración literaria artística entre ambos había sido el libro Jirones Kollavinos (La Paz, 1933). 
día 11 de abril, en el que se dedican párrafos específicos a Olazo (durante el ascenso) y a Apu-Rimak (ya extasiados ante la visión de Machu Picchu):

Toda la pesadez de la marcha es disuelta por la amenidad de las anécdotas que narra Olazo -pintor vernacular- cuyo dinamismo a toda prueba y tenacidad, unidos a su pasión por lo nativo, hacen de él, un elemento valioso en la tendencia americanista del Arte Nuevo. [...]. Se cubren de solemnidad las palabras de Alejandro González, haciendo revivir el arte del pasado. Fanático del ritmo lineal que caracteriza, no solo la arquitectura, sino toda la estética incaica, quiere orientar el futuro Arte Americano ajustándolo a su pureza sintética de planos, a su admirable estilización. (Serrano y Crespo Gastelú, 1938, pp. 76-77).

Salvo estos detalles, y algunas fotografías del viaje conservadas por los artistas e intelectuales bolivianos que formaron parte de la comitiva, no contamos con otros testimonios del mismo. Sí la certeza de amistades sólidas que se fraguaron en esas intensas jornadas y concretamente las que, gracias al archivo de Yolanda Bedregal, podemos certificar a través de la correspondencia, entre ellas las que cimentó tanto con Roberto Latorre como con Apu-Rimak, y que fueron incrementadas epistolarmente a partir del retorno de la "misión boliviana" a La Paz.

\section{Cartas a Yolanda Bedregal. El manifiesto artístico de Apu-Rimak}

De las nutridas cartas de Apu-Rimak a Yolanda Bedregal (Fig. 7), como indicamos oportu-

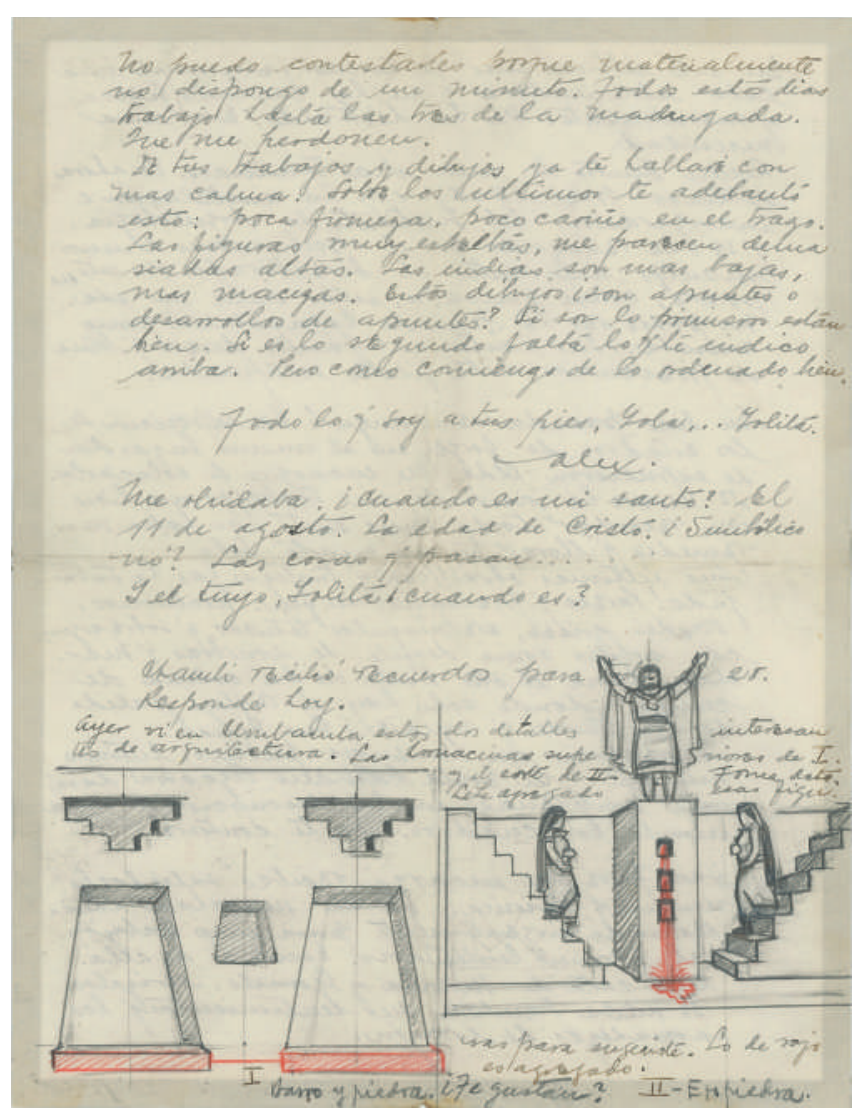

Fig. 7: Carta de Alejandro González Trujillo Apu-Rimak a Yolanda Bedregal, Cusco, junio de 1934. Reverso de una de las hojas. Archivo Yolanda Bedregal, La Paz. namente, hemos rescatado aquellos aspectos que nos permiten detectar parámetros salientes de lo que podríamos denominar su filosofía artística, y entre ellos los que tratan sobre la necesidad de lo espiritual en el arte (utilizamos aquí el símil kandinskyano), la confluencia de la técnica europea con la sensibilidad andina (en línea con el paradigma euríndico de Ricardo Rojas), la trascendencia en cuanto a la significación de las piezas precolombinas más allá de lo puramente formal, y sus estrategias plástico-estéticas acerca de cómo debía interpretarse al indio. Este último punto Apu-Rimak lo asume desde una postura claramente pedagógica, dirigida a transmitir a Yolanda una serie de instrucciones útiles para su propia praxis; así, en cierta manera, asume un papel de maestro y guía para la joven boliviana. En esta línea, 
añadimos también algunos comentarios sobre obras propias y juicios sobre el trasfondo que advertía en la acción artística de artistas peruanos de su época, y de manera específica en la de Teófilo Allaín y José Sabogal. Con respecto a este último, se posiciona decididamente en una acera distinta, criticando su modus operandi y, en concreto, el ejercicio de influencia tendente a frenar el avance de artistas más jóvenes y de quienes no se amolden a sus dogmatismos estéticos.

Para Apu-Rimak era importante la combinación de disciplina, sensibilidad y cultura; para él, la técnica debía estar siempre sometida al corazón, a lo que define como "espíritu". Esta aclaración nos remite a la combinación de lo que César Vallejo llamará, precisamente, "sinceridad": el afecto por una labor en donde confluyen la pasión y la razón. Y todo esto enmarcado en un escenario vivo, andino e indoamericano. Así, el artista le escribe a Yolanda Bedregal, refiriéndose a artistas y estudiantes de su época:

La mayoría de los que te hablo se han preocupado de educar la mano, por su falta de "cultura" no han hecho sino en afanarse en adquirir el oficio, disciplinando el cerebro, pero descuidando el corazón, el espíritu y cuando han querido realizar una obra sentida les ha ganado la mano. Cuántas obras hay técnicamente bien ejecutadas pero frías de emoción.

Y como en nuestro medio, ese oficio se adquiere fatalmente estudiando el occidente, tienes que, cuando conciben una obra, lo hacen bajo esa influencia y cuando quieren interpretar una cosa India salen con esas absurdas mistificaciones. Ni siquiera tienen el valor del primitivismo, que lo tienen, por frío que sea. (AYB. Carta sin fecha)

Con otra carta nos es posible ampliar sus precisiones acerca de la, a veces, difícil confluencia entre la estética europea y la necesidad de "sentir en indio":

Lo otro, su ventanita itodo! inada! Me da la sensación de un cuadro futurista. Esencialmente occidental. Es decir el fruto de la sutileza del refinamiento cultural europeo. Pero se puede hacer sentir en Indio. Cómo? Sometiéndolo al ritmo de la línea, del volumen y del color Indio. Que le parece? Resultaría un capricho, algo como ese cuadro de Guzmán de Rojas del desnudo del lago, ${ }^{10}$ pero más americano. Un poco cerebral pero como disciplina se puede hacer (AYB. Carta del 9 de junio de 1934).

La tradición del arte occidental, entiende, debe servir para recrear, con la técnica, la sensibilidad andina, por eso insiste en "dominar el oficio" y en la "labor manual" para poder revelar lo más puro e intacto de las culturas andinas. Esta apropiación de lo útil para plasmar lo esencial y ancestral es recurrente en las cartas de Apu-Rimak; transcribimos algunos ejemplos de ello:

Lo occidental, libro, música, artes, nos sirve para educar, sutilizar, agudizar nuestra sensibilidad, pero sin dejar de mirar a lo nuestro. Conseguida esta agudización de la sensibilidad, sintonizado con el movimiento moderno; ir con ese espíritu preparado a plasmar la sicología del Indio (de raza o de espíritu) a realizar la Obra. (AYB. Carta sin fecha).

También resultan muy ilustrativos otros fragmentos referidos al "arte indoamericano" y al propio proceso interior que se produce en Apu-Rimak, al entrar en contacto con objetos de arte precolombino, en cuanto a trascender lo formal, arribar a una comprensión de sus significados y alcanzar una consustanciación espiritual con los mismos, como paso previo a la creación de un "arte moderno americano" (Fig. 8). Puesto en perspectiva, estos conceptos anticipaban ideas que desarrollaría, a partir de su regreso a Montevideo, coincidentemente en ese mismo año y después de varias décadas repartidas entre Europa y Estados Unidos, el uruguayo Joaquín Torres-García. Esto es lo que decía Apu-Rimak:

10 Se refiere a América y Europa, pintado en 1933 y expuesto en Cusco al año siguiente. 


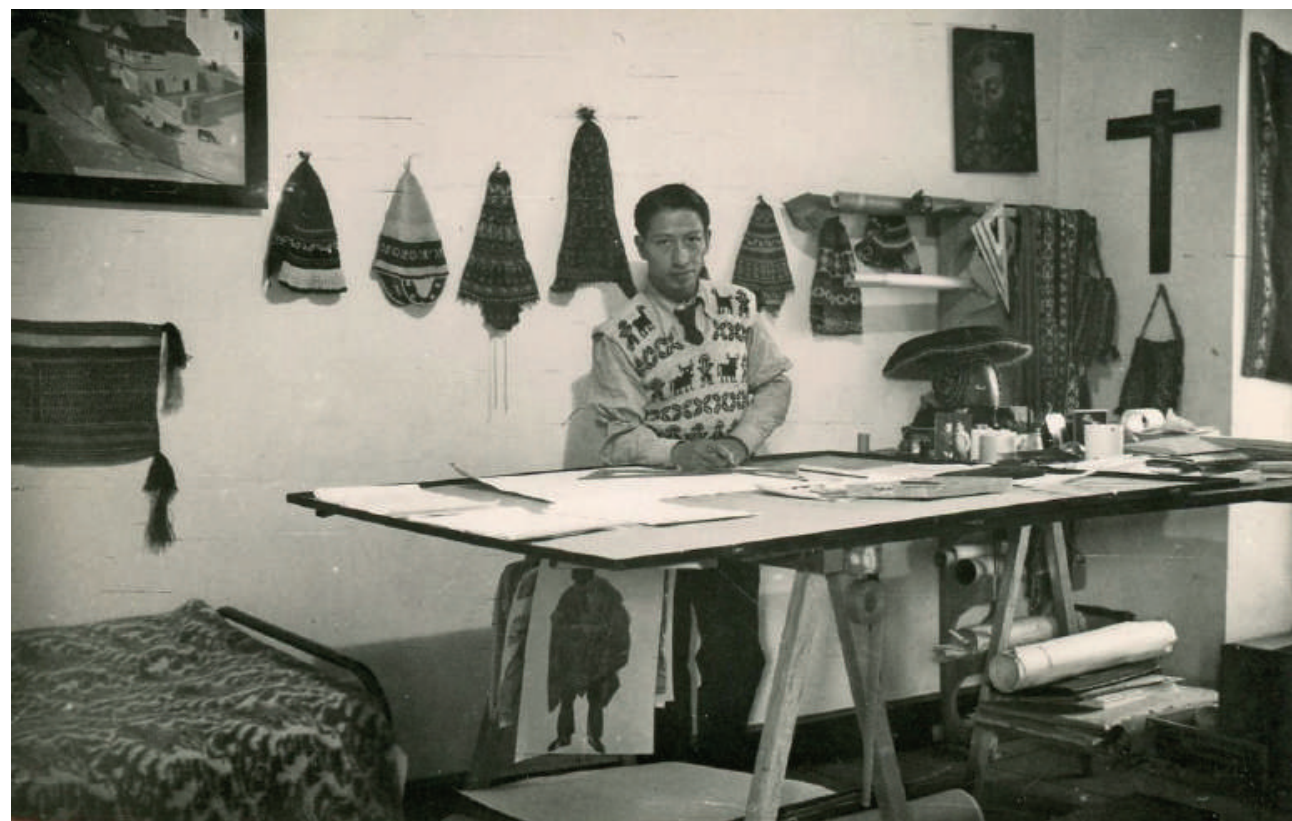

Fig. 8: Alejandro González Trujillo Apu-Rimak en su habitación-taller en Cusco (1934). Gelatina de plata sobre papel. Archivo Yolanda Bedregal, La Paz.

Sabes, después de repasar tus líneas, me das la misma sensación que tenía cuando comenzaba a captar, copiando sin prejuicios artísticos, los objetos de Arte Antiguo Peruano. Entonces sentía una intuición indefinida, agradable.

Sabía que algo quedaba en mí pero que no podía precisar. Esta sensación se sucedía, día tras día, ante cada objeto. Pero a medida que pasaban estas emociones, también día a día parecía que aprisionaba fuertemente algo que estaba en el vacío, ese algo que fluía de los objetos y me iban revelando su espíritu. Hasta que después se hizo conciencia. Llegué a precisar dentro de mí ese espíritu del Arte Indo-Americano.

Ahora voy firme, a interpretar con esa conciencia, con ese espíritu, la realidad actual. Es esto Yola: Hacer Arte Moderno Americano con algo que viene de muy lejos y cuya continuidad no se ha interrumpido. Está arrancado para aquellos miopes occidentalizados, pero para el Indio no. Él mantiene esa continuidad en todas sus manifestaciones espirituales. Solo precisa tener un ojo educado, tener el espíritu sutilizado en esta inquietud para captar esas manifestaciones.

De Occidente por lo mismo que su evolución no ha sido interrumpida, solo tomar las sugerencias de carácter técnico que sirvan para enriquecer nuestros medios de expresión. Nada más que eso. Pero no su espíritu! (AYB. Carta del 14 de mayo de 1934).

Precisamente, para Apu-Rimak, todo estudio de "lo occidental" debía tener como meta la mejor comprensión de lo indígena. El dominio de las técnicas y la claridad en los objetivos permiten una plena dimensión creativa: "Para el artista, una vez logrados los medios de expresión, dominados estos, el resto de su existencia es corta para realizar todo lo que intuye". ${ }^{11}$ Asimismo, la clave para acometer con garantías una trayectoria artística como la suya, radicaba en alcanzar una comprensión total del alma, del modus vivendi de los nativos, expresando a la vez la convicción de que en lo físico también se percibe ese espíritu. La dinámica de este pensamiento entrañaba, pues, no solamente el manejo de conocimientos 
puramente plásticos, sino también una ampliación del espectro disciplinario, incluyendo nociones sobre literatura, arqueología o música.

Otra cosa. Cuando veas a los indios, observa cómo se sientan, se paran, caminan, danzan, y qué actitudes toman. Procura retener la masa, el block. Toma apuntes, aunque no salga acertado pero lo suficiente para recordar, aunque sea ligeramente, la imagen. Y después, desarróllalos en casa. Al comienzo vas a tener una gran resistencia y probablemente te fatigues pronto, pero si este trabajo lo haces continuamente, disciplinadamente, sentirás cómo resuelves lo que no has visto, solo por asociación con otros trabajos anteriores, a fuerza de razonar formas.

...

A esto llamo labor objetiva de interpretación.

A falta de maestros, de orientadores, había que ver la forma de concretar esta inquietud.

En resumen tres formas de llegar a la estilización

I.- Repetir de memoria en casa el estudio detenido realizado en la Academia. Modelo: quieto.

II.- Desarrollo del apunte ligero tomado en la calle, auxiliado por el recuerdo visual o emotivo. Modelo: muy pocos segundos quieto y casi siempre en movimiento.

III.-Copia fiel de los motivos o modelos antiguos americanos. Para penetrarse en su espíritu: Ritmo de volumen en la forma y en el color.

Arte esencialmente sintético.

Como disciplina literaria te recomiendo esto: Leer cuanto se ha producido en verso o prosa, sobre motivos americanos indios. Inspira tus bocetos en estos temas. De los libros de arqueología aquellos estudios en que tratan de interpretación de imágenes. Generalmente en estos trabajos se intuyen algunas revelaciones plásticas. Asocia las sugerencias plástica literarias con las imágenes que te den la interpretación de las últimas o sea lo que surge de los estudios arqueológicos.

En música, procura aprender aires indígenas, trata de asociar el ritmo de estos con el ritmo plástico, forma y color de las cosas antiguas.

Así, las otras inquietudes artísticas: literatura o música, girarán alrededor de lo Indio y las intuiciones que surjan de ellas, colaborarán para la mejor interpretación plástica (AYB. Carta sin fecha).

$\mathrm{Al}$ recomendarle datos para un curso que debe impartir Bedregal, retoma Apu-Rimak temas como el ritmo y la cadencia indígenas, es decir, la existencia de un compás andino como forma de ver el mundo, contrapuesta a la "occidental". De alguna manera nos remite a esa filosofía vallejiana de "confianza en el anteojo, no en el ojo"; es esa medida del tiempo, del movimiento, lo que descubre aquello que podría considerarse una resistencia, un vínculo con los saberes antiguos de la supervivencia:

Observa: El Indio es constante en su labor: labra la tierra, teje, negocia sin perder el ritmo en sus diferentes actividades, es decir lleva una vida equilibrada. Por eso su relativo conformismo ante las tremendas injusticias que se realizan con ellos. Por eso también lo difícil de sacarlos de su ritmo acompasado, lento y someterlo a otro ritmo más acelerado y moderno.

Solo así, con esa constancia rítmica, pudo realizar obras tan maravillosas en épocas diferentes y crear estilos regionales diferentes sin perder su unidad, su espíritu, su equilibrio integral.

Para mi el espíritu Indoamericano es la afinidad de estilos diferentes equilibrados dentro de un solo ritmo.

Por eso, Yola: saquemos el Indio constante en su labor que tenemos metido adentro y hagamos que prime su valor sobre el espíritu decadente, enervante del occidental sensiblero, sensual, abúlico que también tenemos metido muy dentro.

Así es que: Estudiar, Enseñar, Orientar y Encontrarse (AYB. Carta del 29 de abril de 1934). 
Es precisamente la educación lo que define el trabajo constante y "disciplinado" de González Trujillo, quien no se dedicó únicamente a laborar para el Instituto Arqueológico del Cusco, lo cual le demandaba no solamente disponer del tiempo que requerían los viajes, sino también la realización de apuntes y dibujos, y las tareas de clasificación de material; además de todo ello, impartió clases, tanto en la Academia de Bellas Artes de la ciudad, como en escuelas fiscales. La educación y la pedagogía son constantes preocupaciones que vincula con el mal manejo de los gobiernos. A mediados de 1934, le escribe a Bedregal:

Continúo la catalogación de las formas de la cerámica Inka en el museo de la Universidad. Labor en la Comisión Técnica. Clases de Honor en dos escuelas fiscales. Colaboración gráfica en el "Bureau de prensa aprista". Clases de orientación americana en la Escuela de Arte Libre de la Sociedad de Bellas Artes y una docena de álbums que me han caído como llovidos del cielo. En la E de BA orientación sobre Arte Americano (AYB. Carta del 15 de junio de 1934).

Descarga su frustración sobre la situación de los estudiantes de nivel elemental, demostrando la falta de estímulo y el escaso conocimiento de sus propias culturas:

Qué difícil es hacer entender estas cosas a los muchachos, sobre todo a los logrados que oponen una resistencia terrible, a pesar que presienten su caída si no se amoldan a estas sugerencias. Los que empiezan responden mejor, son más asequibles. Labor ardua.

En una escuela fiscal, doy clases de Arte Peruano al $5 .^{\circ}$ año de primaria. Después de varias clases hice un ensayo de exploración sobre la capacidad retentiva visual y emotiva de estos niños. Te imaginas Yola: les preparé el ánimo, les hablé del paisaje del Cuzco, su belleza, su vida, flora, fauna, tradición, los indios, las escenas, en fin de todo: 90 niños apretujados en 30 bancas que parecían cepos de tortura. Ni uno respondió, ninguno dio ni siquiera idea de lo que era el Cuzco ni su ambiente. Resultado: una tragedia dolorosa. Todo efecto de la influencia occidental: hicieron botes, buques, molinos de viento holandeses, caballos de "pur sang", casa de cartón iSin tejas!, etc. etc. iQué decepción Yola! Todo debido a la grave falta de los maestros de descuidar la educación de la sensibilidad.

iHay derecho de conformarse con este estado de la educación? Es un crimen sin nombre: Qué patriotismo, ni qué nacionalismo se puede exigir a estos futuros hombres que no sienten su medio. Es doloroso. Pero yo no desmayaré. Prefiero claudicar con mi vida. La responsabilidad es apremiante (AYB. Carta del 15 de junio de 1934).

En abril de 1934, nombran a Yolanda profesora de Historia del Arte en la Escuela de Bellas Artes en La Paz. Al enterarse, Apu-Rimak le aconseja lo siguiente:

Esto te va a servir mucho, porque te disciplinará. Se creará en ti el sentido de responsabilidad para con tu puesto y de reflejo influirá notablemente en tu labor personal. Porque al tratar de explicar a los alumnos, en la forma más sentida posible, el proceso evolutivo del Arte, por labor comparativa consciente o subconsciente, objetiva o subjetiva comprenderás lo que es el equilibrio en todas las manifestaciones clásicas del Arte. Y tratarás de buscar este equilibrio en tu camino. Y ese equilibrio no se consigue sino a fuerza de estudio, de introspección diaria, de búsqueda continua.

Esto, aparte de la labor técnica diaria que tienes que realizar para formarte o definir tu estilo, tu factura personal. Es una brillante oportunidad para que te traces un plan de trabajo intenso sin llegar al agotamiento (AYB. Carta del 29 de abril de 1934).

Estas y muchas otras cuestiones de cariz pedagógico y estético se reflejan en las cartas de Apu-Rimak, conformando esto que hemos caratulado como su "manifiesto artístico". No faltan comentarios puntuales acerca de obras en concreto (inclusive, el envío de algunas de ellas) ni reflexiones acerca del ámbito artístico peruano, a todas luces reveladoras, como se podrá apreciar en los documentos que elegimos para transcribir aquí.

No solamente le llegan a Yolanda pequeñas obras de Apu-Rimak (Figs. 9 y 10). El envío de dos xilografías de Teófilo Allaín, una destinada a ella y otra a Marina Núñez del Prado, se convierte en la excusa perfecta para trazar una radiografía del actual panorama artístico 


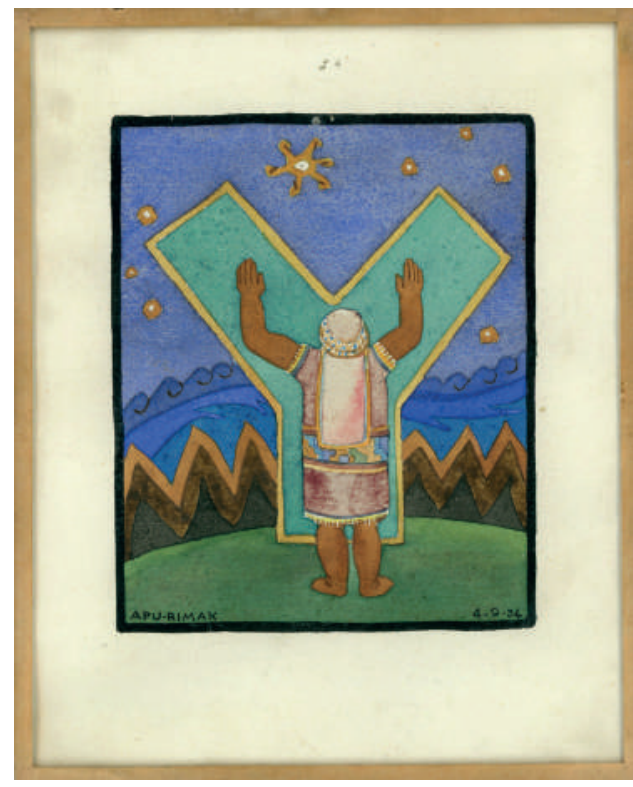

Fig. 9: Alejandro González, Apu-Rimak. Capitular para Yolanda Bedregal (4 de septiembre de 1934). Lápiz y acuarela sobre papel, 17.5 x $14 \mathrm{~cm}$. Archivo Yolanda Bedregal, La Paz.

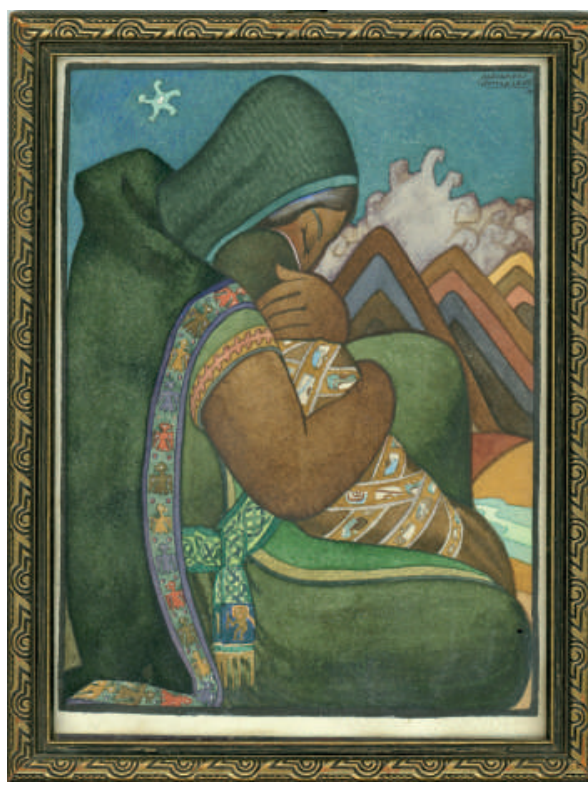

Fig. 10: Alejandro González Apu-Rimak. Maternidad indígena (1935). Lápiz y acuarela sobre papel, 22 x $17 \mathrm{~cm}$

(marco incluido). Archivo Yolanda Bedregal, La Paz.

peruano, dominado entonces, institucionalmente, por la llamada escuela indigenista comandada por José Sabogal. ${ }^{12}$

El correo pasado me quedé con el deseo de enviarte el dibujito del estudio y dos grabados de madera de un muchacho Allaín pintor que se destaca de la última hornada de la E. de B.A. de Lima, quien simpatizando con Uds. por lo mucho que hablé de Marina y de Yola, les ha dedicado un grabado a cada una. Allaín es uno de aquellos que aceptaban mis argumentos para iniciar la reforma de la Escuela, pero que por tolerancia sentimental con el anciano Director de la Escuela, niño al fin, se abstuvo de colaborar en el movimiento iniciado por mí y otros. Afortunadamente, para él, el tiempo se encargó de demostrarle que fue un error el mantenerse al margen de las reivindicaciones que propugnábamos, influido más que nada por el conjunto de muchachas, quienes como allá acudían por adquirir un adorno más capacitados y mejor intencionados, alegando esa actitud sentimental: icomo que les importaba poco el futuro!

En efecto, un año más tarde, cuando en una exposición de fin de año, este chico quiso exponer unos grabados, los maestros a quienes defendía y particularmente Sabogal, que reclama para sí los títulos más honrados como vanguardista, con una actitud solapada, indigna en un artista, se opuso a que exhibiera aquellas maderas, manifestando que en la Escuela no se enseñaba grabado ¿Cabe mayor acusación de incapacidad de orientación de directores y maestros?

Pero Sabogal, era grabador que publicaba con regularidad sus trabajos en diarios y revistas ¿Por qué ese proceder? ¿Por incapacidad de enseñar o por egoísmo? Innegablemente esto último: por temor de que los que vienen atrás lo superen e interesado sobre todo en oponerse a todo aquel que hiciera labor sin ir asido al carro de su tendencia; por

12 El Primer Salón de los Independientes, celebrado en el Palacio de la Exposición (Municipalidad) de Lima a inicios de 1937 marcará un punto de inflexión en la acción emancipatoria de un amplio grupo de artistas con respecto a los dictamentes de la ENBA y la vigente hegemonía oficialista, sabogaliana (Ver: Castrillón Vizcarra, 2001). En ese año, Apu-Rimak, quien no participó de dicho Salón, partió hacia París para trabajar junto a Valcárcel en el pabellón peruano de la Exposición Internacional. 
no perder esa posición de portaestandarte tan fácilmente adquirida a base de bombos y relaciones periodísticas, epatando la ignorancia de los pseudo críticos de diarios y revistas. Estos, como ya se sabe, basados en la crítica emotiva, ocultan su ignorancia de lo que debe ser la cultura artística integral, que precisan para oficiar de crítico, pero que sí pueden encumbrar a cuanto personaje se les ocurre, importándoles muy poco establecer tendencias y jerarquías que existen entre los cultores de cualquier rama del arte. En un pueblo ignorante, inculto, pese a la ranciedad de su abolengo vivencial, ya se sabe como acoge con fervor, estas iniciativas periodísticas.

Aquí, Allain, en su estadía de casi cuatro meses, con mis charlas y con el ambiente ha objetivado mis intuiciones confirmando todo lo que ya le había dicho desde Lima (AYB. Carta del 24 de noviembre de 1934).

En relación con su dinámica profesional, la propia conciencia social de Apu-Rimak choca muchas veces con la necesidad individual de dedicarse plenamente a su obra y su proyecto artístico. Esto tiene un costo para él, confesado a Yolanda en la carta del 4 de junio de 1934: "Pero ahora quisiera vivir mi vida. Siento la necesidad de romper con todo... y no puedo. Esta emoción social, este deber para con los demás me tiene trabado: si vivo mi vida claudico con los demás, si me doy a los demás claudico conmigo mismo. Qué hacer? Terrible responsabilidad".

Quizá ese "vivir la vida” logra su cristalización con el pronto inicio de la serie de viajes para visitar in situ los conjuntos incaicos del sur del Perú y Bolivia, los cuales emprenderá entre 1934 y 1936 junto al historiador y antropólogo Luis E. Valcárcel, periplos a los que se sumarán el arquitecto Emilio Harth-Terré y el fotógrafo Abraham Guillén (Romero Sommer, 2011, p. 25). Se lo anuncia a Yolanda Bedregal en abril de ese año:

Acabo de recibir del Ministerio de Lima un oficio adscribiéndome a la comisión encargada de preparar una Historia de la Cultura Inkaika. Prorroga mi estadía en el sur del Perú por todo el resto del año y brinda posibilidades de viajar. Preside la comisión el Dr. Valcárcel y lo formará el Ingeniero Arquitecto Harth-Terré (aquel de la barbita de ojos claros que estaba en el Museo del Comité y autor de un artículo sobre la exposición Boliviana) del Archivo Nacional de Lima, el fotógrafo Guillén del Museo de Arqueología, yo, como pintor y dibujante del mismo y otros miembros que aun no los conozco. En Junio recorreremos Puno y todas las poblaciones de alrededor del lago. Visitaremos Tiahuanaku y casi seguro los museos de La Paz. Estoy felicísimo. Con este viaje defino mi personalidad, Yola (AYB. Carta del 29 de abril de 1934).

Los lugares que recorre en esos meses despiertan en él asombro y admiración:

El Altiplano, Yolita, es una región maravillosa. Es tan limpio todo, tan definido el paisaje, sin la complicación barroca de estos valles del Cuzco, que las figuras y las cosas adquieren una precisión insospechada. Es un ambiente esencialmente escultórico. Y pictóricamente tienen sus matices toda la claridad y amplitud de gama de las telas antiguas. Y esto que no he ido en la mejor época. iCómo será cuando los campos están floridos! Algo como para morirse en arco iris (AYB. Carta del 1 de octubre de 1934).

Apu-Rimak se refería a trayectos realizados el mes anterior, acompañando a Valcárcel, entre Perú y Bolivia: Pukara, Lampa, Puno, Ichu, Chucuito, Ácora, Ilave, Juli, Pomata, Yunguyo, Copacabana, Isla del Sol. ${ }^{13}$ Sobre este recorrido le informa a Bedregal: "la cantidad de datos y apuntes... eran tantos y había necesidad de desarrollarlos inmediatamente para que Valcárcel presente su informe al Gobierno...”. La existencia de una frontera entre Perú y Bolivia le parecía absurda, y comenta en la misma carta:

Para mí, el Altiplano, el Kollao como decimos nosotros, es la región que eleva, es la región del sur del Perú que encierra más optimismo, por la inquietud de sus hombres

13 Debido al mal tiempo no alcanzaron a llegar a Tiwanako y La Paz, frustrándose la posibilidad de un encuentro con Yolanda. 
y por la realización de estas inquietudes y en parte están realizando a la medida de sus posibilidades.

Qué absurda limitación geográfica la que señalaron los hombres del pasado. No puede haber error más grande. Particularmente yo, al pasar la frontera sentí la imposición de la cosa protocolar. Una especie de cohibimiento para manifestar mi dolor ante la tragedia de ver una ciudad sin jóvenes, sin alegría. Hasta la bandera que oteaba en lo alto de un edificio tenía sus colores pálidos. No estaba como la banderita que me acompaña y que me regalaste aquella noche. Solo las polleras de las cholas domingueras que volvían de Yunguyo de hacer el mercado, gritaban alegría a lo largo del camino. Será porque para estas no existe la frontera ni comprenden qué es eso (AYB. Carta del 1 de octubre de 1934).

En carta de escasos días después, describe su visita a Pukara: "Un pueblecito de gran tradición como centro cerámico, pues su fama viene desde la época precolombina”. Destacan algunas observaciones suyas que demuestran su labor en estos recorridos, así como su profundo deseo de investigar y desentrañar la historia:

Arqueológicamente Pukara tiene un gran valor. Intuyendo a través de la importancia que como pueblo alfarero tiene en la actualidad, hicimos un recorrido por sus alrededores guiados por unos muchachos ceramistas Iturri. ${ }^{14}$ Descubrimos una serie de 14 o 15 estelas muy interesantes y hallamos fragmentos valiosos de cerámica antigua. Estos y aquellas por sus motivos y estilo de ornamentación revelan el gran valor que Pukara tiene para aclarar muchos problemas sobre la evolución y desenvolvimiento del Arte en América.

Para mi, creo que aquí, el estilo Tiawanako, sufrió una transformación e irradió al norte creando el estilo primitivo conocido con el nombre de Andino; que después por asimilación y evolución local dieron origen a los otros estilos definidos. También creo que aquí (Pukara) se produjo la fusión del estilo Inka con el Tiawanako, creando algunas formas y ornamentación que se apartan del estilo típico Inka, cuya aparición me hacía sospechar ya sobre su posible mistificación.

Un trabajo serio de exploración e investigación en este sector daría mucha luz acerca de estos problemas. (AYB. Carta del 5 de octubre de 1934).

Es notable el efecto que el paisaje y las ruinas despertaban en el artista. Muy a menudo sus descripciones parecen lienzos y hay una visión poética de lo que lo rodea: es un artista enamorado de su entorno y muy especialmente de Kosko, como escribía al referirse a la ciudad, subyugado también por un legado que él percibe en el hombre americano: "Te advierto que a través de mi búsqueda siento al indio esencialmente plástico, formal" ( $\mathrm{s} / \mathrm{f})$. Estas experiencias, como puede colegirse, se consolidaban entonces como punto culminante de la trayectoria de Apu-Rimak; en forma paralela, Yolanda Bedregal transitaba decididamente hacia la literatura.

\section{Lo que vino después... Palabras finales}

Los tiempos vitales de ambos se fueron acelerando: en abril de 1936, a Yolanda le fue otorgada una beca por el Barnard College de la Universidad de Columbia y pocos meses después puso proa a Estados Unidos. ${ }^{15}$ Apu-Rimak, después de un viaje a Buenos Aires, ciudad en la que estableció amistad con sus compatriotas Juan Manuel Ugarte Eléspuru, Sérvulo Gutiérrez y Pablo Soldi, partía hacia París en 1937. Su viaje hacia la capital francesa incluyó escala en Nueva York, desde donde le escribe a Yolanda la última carta de la serie, el 25 de enero; aparentemente no llegaron a coincidir allí.

14 Se refiere seguramente a los hermanos Pablo Francisco y Juan Iturry.

15 Antes de partir desde La Paz había dejado en manos de su familia los manuscritos que conformarían, en 1937, su primer libro de poesías, Poemar, que incluía una serie de "Apuntes cuzqueños". 
Apu-Rimak hizo ese viaje a París en carácter de dibujante del Museo Nacional, para colaborar con Luis E. Valcárcel, concretamente en la decoración del pabellón peruano de la Exposition Internationale des Arts et Techniques dans la Vie Moderne celebrada ese año. Aplicó al pabellón motivos mochicas, nazca, tiawanacotas e incaicos, ${ }^{16}$ y destacó también por el monumental lienzo (sobre tocuyo) El arte y la técnica en el antiguo Perú. ${ }^{17}$ En ese tiempo, junto a Valcárcel y al pintor Jorge Muelle, que también había trabajado en la puesta en escena del pabellón peruano, Apu-Rimak frecuentaría al etnólogo francés Paul Rivet (Romero Sommer, 2015), quien ese mismo año, coincidiendo con la Exposición Internacional, había creado el Musée de l'Homme sobre la base del Musée d'Ethnographie du Trocadéro. Sin duda, un cierre significativo para un viaje que se prolongaría durante algunos meses más, antes del retorno al Perú en 1939, coincidiendo con el inicio de la Segunda Guerra Mundial.

Para ese entonces, los caminos de Apu-Rimak y Yolanda Bedregal llevaban largo tiempo bifurcados. Distanciadas las sendas comunes de expresión artística y en pleno desarrollo de sus respectivos proyectos vitales, él entregado a las artes plásticas como artista y docente, y ella a la escritura (su obra la constituyen cinco tomos, dos de poesía, dos de ensayo y uno de narrativa), el vínculo tiende a desvanecerse. No deja de ser curioso que ambos ensayaran con las expresiones artísticas del otro; Yolanda siguió modelando, aunque entregada a la escritura; Apu-Rimak le escribe un poema en inglés en la última misiva. Nos queda de esta historia, en definitiva, la valoración, el respeto y el aprecio de Yolanda hacia "Álex", plasmados en el resguardo de sus cartas, con palabras que nos llegan casi un siglo después, dotadas de la fuerza de lo auténtico, de la pasión y de la entrega de un artista cabal a su causa. Y que, desde Bolivia, permiten recuperar el credo artístico, hasta ahora inédito, redactado de su puño y letra, de una figura tan esquiva como esencial para la historia del arte peruano.

16 Esta acción nos recuerda a la que Manuel Domingo Pantigoso había realizado en el pabellón peruano de la Exposición Iberoamericana de Sevilla de 1929.

17 Esta obra, de 170 × $633 \mathrm{~cm}$, se conserva en la Municipalidad de Miraflores. 


\section{Referencias bibliográficas}

Bedregal, Y. (2009). Obra Completa. 5 vols., La Paz: Plural.

Castrillón Vizacarra, A. (2001). Los independientes. Distancias y antagonismos en la plástica peruana de los años 37 al 47. Lima: ICPNA.

Echazú Conitzer, A. (2019). "Nuestro domingo: crónica epistolar entre Yolanda Bedregal e Iván Rimša”. En: Ciencia y Cultura. $\mathrm{N}^{\circ}$ 43, diciembre de 2019, pp. 225-239. La Paz: Universidad Católica Boliviana "San Pablo".

Gutiérrez Loayza, J. G. (1994). Sesenta Años de Arte en el Qosqo 1927-1988. Cusco: Municipalidad del Cusco.

Gutiérrez Viñuales, R. (2019). Modernos y americanos. Las artes en la ruta CuzcoBuenos Aires. Ciencia y Cultura. En: Ciencia y Cultura. $\mathrm{N}^{\circ} 43$, diciembre de 2019, pp. 273281. La Paz: Universidad Católica Boliviana "San Pablo".

Kuon Arce, E.; Gutiérrez Viñuales, R.; Gutiérrez, R. y Viñuales, G. (2009). Cuzco-Buenos Aires. Ruta de intelectualidad americana (19001950). Lima: Universidad San Martín de Porres, Fondo Editorial.

Kusunoki, R. (2018). "La escuela sabogalina: apogeo y crisis del indigenismo, 19301943". En Cruz, Pablo (ed.). Escuela Nacional Superior Autónoma de Bellas Artes del Perú. Centenario, 1918-2018, pp. 93-123. Lima: ENSABAP.
Latorre, R. (1938). Prólogo. En: Serrano, G.; Crespo Gastelú, D. Tierras del Kosko, pp. 9-10. La Paz (Indoamérica): Editorial Renacimiento.

Núñez del Prado, M. (1973). Eternidad en los Andes. Memorias de... Santiago de Chile: Álvaro Flaño.

Riobó Pezoa, E. (2019). "Hablar desde la entraña: humanismo, nación y condición femenina en Yolanda Bedregal". En: Ciencia y Cultura. $\mathrm{N}^{\circ} 43$, diciembre de 2019, pp. 2748. La Paz: Universidad Católica Boliviana "San Pablo".

Rocha Velasco, O. (2019). "Tres indigenismos a través de periódicos y revistas literarias y culturales (1930-1950)". En: Ciencia y Cultura. $\mathrm{N}^{\circ} 43$, diciembre de 2019, pp. 250259. La Paz: Universidad Católica Boliviana "San Pablo".

Romero Sommer, M. S. (2011). Apu-Rimak. Alejandro González Trujillo (1900-1985). Lima: Asociación Cultural Peruano Británica.

Romero Sommer, M. S. (2015). Apu-Rimak. Alejandro González Trujillo (Apurímac, 1900Lima, 1985). Tesis de Magíster en Arte Peruano y Latinoamericano. Lima: Universidad Nacional Mayor de San Marcos.

Serrano, G.; Crespo Gastelú, D. (1938). Tierras del Kosko. La Paz (Indoamérica): Editorial Renacimiento.

Recibido el 1 de septiembre de 2020 Aprobado el 16 de septiembre de 2020 